\title{
Correlative and comparative study of Fishman's skeletal maturity indicators with CVMI and chronological age in Lucknow population
}

\author{
Sachan Kiran, V. P. Sharma, Pradeep Tandon \\ Department of Orthodontics and Dentofacial Orthopedics, Babu Banarasi Das College of Dental \\ Science, KGMC, Chandra Dental College, Safedabad, Barabanki, Lucknow, Uttar Pradesh, India
}

\author{
Address for correspondence: \\ Dr. Sachan Kiran, \\ 2/894 Sec-H Kursi Road, Jankipuram \\ Lucknow, Uttar Pradesh, India. \\ E-mail: drkiransachan@yahoo.in
}

\begin{abstract}
Objective: The present study consists of comparison and correlation between the hand-wrist skeletal maturation indicator (SMI) and the cervical vertebral maturation indicator (CVMI) and verification of the reliability of the vertebral index and chronological age in the determination of the stages of the skeletal maturation. Materials and Methods: The study consisted of randomly selected 90 children from Lucknow population with 45 males (age range 10-13 years) and 45 females (age range 9-12 years). Hand wrist radiograph taken for SMI, Lateral cephalogram taken for CVMI. Correlation was made between cervical vertebrae maturation and hand wrist maturation. These two methods and the chronological age were compared using the Newman-Keuls test. Results: There was strong correlation between SMI and CVMI for both male and female $(0.849,0.932)$. Cervical vertebrae maturation indicator and hand-wrist skeletal maturational indicator (SMI) showed no statistical significant difference for males and females. However, females showed maturation at an early age as compared to males. Chronological age shows significant difference in comparison to skeletal age. Conclusion: It was concluded that CVMI stages can also be used as for assessing skeletal maturity. Cervical vertebrae assessment provided a reliable assessment for pubertal growth spurt, it would be beneficial to use a lateral cephalogram for skeletal maturity assessment and thereby eliminate the need for an additional radiograph (hand-wrist radiograph). This is cost effective and will also reduce the radiation exposure to the patient.
\end{abstract}

Key words

Cervical vertebrae, hand-wrist, pubertal growth spurt, skeletal age

\section{INTRODUCTION}

Human growth shows considerable variation in the chronologic ages at which individual children reach similar developmental events. Chronologic age alone is not sufficient for assessing the stage of development of a growing child. Accurate information is provided by developmental stages, such as skeletal maturation, secondary sexual characters, and maturation of different tissue system.

Sexual maturation characteristics, chronologic age, dental development, height, weight and skeletal development are some of the more common means that

\begin{tabular}{|l|l|}
\hline \multicolumn{2}{|c|}{ Access this article online } \\
\hline Quick Response Code: & Website: \\
\hline & www.ejgd.org \\
\cline { 2 - 3 } & \\
\hline
\end{tabular}

have been used to identify stages of growth. ${ }^{[1]}$ One of the important diagnostic tools currently used in determining whether pubertal growth has started, is occurring, or has finished is the hand-wrist radiographic evaluation. ${ }^{[2,3]}$ Hand-wrist radiographs have been used in many ways by different investigators for assessment of skeletal maturity. However, for assessing skeletal maturation, changing concavities on lower border of cervical vertebrae are also found to be a reliable method apart from hand-wrist radiograph. ${ }^{[4]}$ Since cervical vertebrae are already recorded on lateral cephalogram, this eliminates the need for an additional radiographic exposure in orthodontic practice. Now cervical vertebrae skeletal maturation is also found to be a reliable method apart from hand-wrist radiograph.

Determination of maturation and subsequent evaluation of growth potential during preadolescence or adolescence is extremely important. Maturational status can have considerable influence on diagnosis, treatment goals, treatment planning and the eventual outcome of orthodontic treatment. Clinical decisions regarding use of extra-oral traction forces, functional appliance, extraction versus non-extraction treatment, or orthognathic surgery requires growth consideration. 
The present study was conducted:

- To evaluate hand-wrist radiograph and lateral cephalogram (cervical vertebrae) for assessing skeletal age.

- $\quad$ Compare and correlate CVMI with SMI for different age subgroup.

- Validity and applicability CVMI and chronologic age in assessing skeletal age of a patient.

\section{MATERIALS AND METHODS}

The present study was based on lateral cephalometric radiographs, and hand-wrist radiographs of 90 samples. The sample consisted of 45 male (age ranges 10-13 years) and 45 females (age ranges 9-12 years). The samples for the study were selected from the Dental outpatient Department of Orthodontics, Faculty of Dental Sciences, King George's Medical College and from various schools of Lucknow.

All the subjects divided in to two groups: Group 1 consisted of males and Group 2 consisted of females. Each group was further divided into 3 subgroups on the basis of age. Table 1: Showing subject grouping.

\section{Criteria for case selection}

1. All the subjects selected were moderately built and are of growing age with no history of deformities, bone diseases and major illness in the past.

2. None of the subjects showed any facial asymmetry.

3. No history of trauma or surgery in the dentofacial region.

4. The subjects with muscular dystrophy, congenital abnormalities affecting growth and development, traumatic lesions of cervical vertebrae, jaw, hand and wrist were excluded.

\section{Methods}

Lateral cephalometric radiograph of each individual was taken with a universal counter balancing type of cephalostat at the faculty of Dental Sciences, King George's Medical College, Lucknow. Kodak' X-ray films (8"×10") were exposed to $70 \mathrm{KVp}, 45 \mathrm{MA}$ for an average of $1.8 \mathrm{sec}$, With a tube to film distance of 6 feet. A hand-wrist radiograph and a lateral cephalogram were made for each of the subjects at same day after duly obtaining consent. An ethical clearance was obtained with regard to the radiographic exposure of the subject. Prior to exposure for radiation, suitable patient protection devices were used.

Hand-wrist radiograph was taken by placing the left and right hand and wrist on the cassette with fingers slightly separated. Screen film and target film distance was used $90 \mathrm{~cm}$. The film was exposed to $20 \mathrm{~mA}$ current for an average of 0.5 seconds. Skeletal maturation of hand-wrist and cervical vertebrae seems to be involved in the pubertal growth spurt. The pubertal growth spurt was considered to be an advantageous period for various types of orthodontic therapies. Hand wrist radiograph taken for SMI, Lateral cephalogram taken for CVMI. Correlations were made among cervical vertebrae maturation and hand wrist maturation. These two methods and the chronological age were compared using the Newman-Keuls test.

In the present study, radiographic interpretation was made as per the system developed to interpret skeletal maturation given by;

Lamparski (1972); ${ }^{[4]}$ on lateral cephalogram, the cervical vertebrae as Cervical vertebrae maturity indicators (CVMI) as in [Figure 1]. Showing correlation between SMI given by Fishman and CVMI stages in [Figure 2].

Fishman (1981); ${ }^{[5]}$ on hand wrist radiographs as skeletal maturity indicator (SMI) [Figure 3].

\section{Skeletal maturity indicators by Fishman}

In this Fishman uses only four stages of bone maturation, all found at six anatomical sites, locked on the thumb, third finger, fifth finger and radius as seen in Figure 3. Eleven discrete adolescent skeletal maturational indicators (SMIs) covering the entire period of adolescent development, are found on these six anatomical sites.

\section{Cervical vertebrae maturational indicator (CVMI) by Lamparski}

Lamparski's standards (1972) were utilized. On each individual lateral cephalometric radiograph the cervical

\begin{tabular}{|c|c|c|c|c|c|}
\hline \multicolumn{3}{|c|}{ Group I (Male) } & \multicolumn{3}{|c|}{ Group II (Female) } \\
\hline $\begin{array}{l}\text { Sub } \\
\text { group }\end{array}$ & $\begin{array}{c}\text { Age } \\
\text { (years) }\end{array}$ & $\begin{array}{c}\text { No. of } \\
\text { subjects }\end{array}$ & $\begin{array}{l}\text { Sub } \\
\text { group }\end{array}$ & $\begin{array}{c}\text { Age } \\
\text { (years) }\end{array}$ & $\begin{array}{c}\text { No. of } \\
\text { subjects }\end{array}$ \\
\hline$a_{1}$ & $10-11$ & 15 & $a_{2}$ & $9-10$ & 15 \\
\hline$b_{1}$ & $11-12$ & 15 & $b_{2}$ & $10-11$ & 15 \\
\hline \multirow[t]{2}{*}{$c_{1}$} & $12-13$ & 15 & $c_{2}$ & $11-12$ & 15 \\
\hline & Total & 45 & & Total & 45 \\
\hline
\end{tabular}

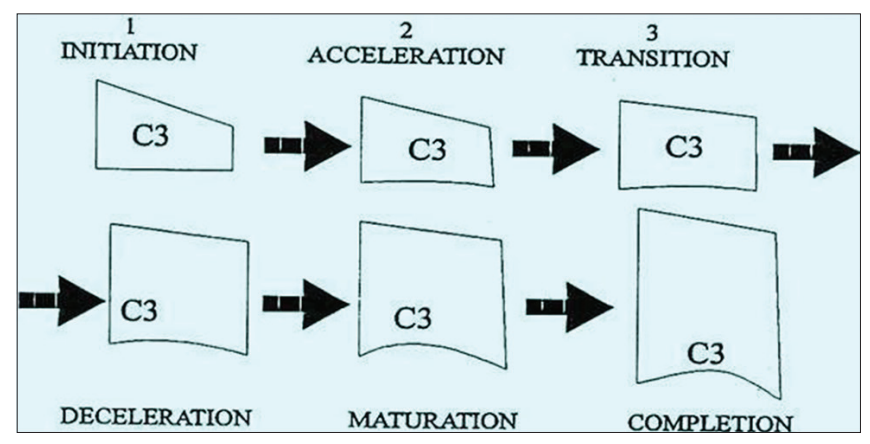

Figure 1: Cervical vertebrae maturation indicators using $C_{3}$ as a guide 
vertebrae were matched to a standard and assigned the stage which they most closely resembled. He made six stages of CVMI [Figure 1].

\section{correlation between CVMI and SMI}

In this we correlate the stages of CVMI and SMI as in Figure 2 .

\begin{tabular}{|c|c|c|}
\hline CVMI - 1 & $\begin{array}{l}\text { 1. Initiation } \\
\text { very significant amount of adolescent growth } \\
\text { expected. } \\
\text { C2, C3 and C4 inferior vertebral body } \\
\text { borders are flat. } \\
\text { Superior vertebral borders are tapered } \\
\text { posterior to anterior. }\end{array}$ & SMI 1\&2 \\
\hline CVMI - 2 & $\begin{array}{l}\text { 2. Acceleration } \\
\text { Significant amount of adolescent growth } \\
\text { expected. } \\
\text { Concavities developing in lower borders of } \\
\mathrm{C} 2 \text { and } \mathrm{C} 3 \text {. } \\
\text { Lower border of } \mathrm{C} 4 \text { vertebral body is flat. } \\
\mathrm{C} 3 \text { and } \mathrm{C} 4 \text { are more rectangular in shape. }\end{array}$ & SMI $3 \& 4$ \\
\hline CVMI - 3 & $\begin{array}{l}\text { 3. Transition } \\
\text { Moderate amount of adolescent growth } \\
\text { expected. } \\
\text { Distinct concavities in lower borders of } \mathrm{C} 2 \\
\text { and } \mathrm{C} 3 \text {. } \\
\mathrm{C} 4 \text { developing concavity in lower border of } \\
\text { body. } \\
\mathrm{C} 3 \text { and } \mathrm{C} 4 \text { are rectangular in shape. }\end{array}$ & \\
\hline CVMI - 4 & $\begin{array}{l}\text { 4. Deceleration } \\
\text { Small amount of adolescent growth } \\
\text { expected. } \\
\text { Distinct concavities in lower borders of } \mathrm{C} 2 \text {, } \\
\mathrm{C} 3 \text { and } \mathrm{C} 4 \text {. } \\
\text { C3 and } \mathrm{C} 4 \text { are nearly square in shape. }\end{array}$ & \\
\hline CVMI - 5 & $\begin{array}{l}\text { 5. Maturation } \\
\text { Insignificant amount of adolescent growth } \\
\text { expected. } \\
\text { Accentuated concavities of inferior vertebral } \\
\text { body borders of } C 2, C 3 \text { and } C 4 \text {. } \\
\text { C } 3 \text { and } C 4 \text { are square in shape. }\end{array}$ & \\
\hline C3 & $\begin{array}{l}\text { 6. Completion } \\
\text { Adolescent growth is completed } \\
\text { Deep concavities are present for inferior } \\
\text { vertebral body borders of } \mathrm{C} 2, \mathrm{C} 3 \text { and } \mathrm{C} 4 \text {. } \\
\text { - } 3 \text { and } \mathrm{C} 4 \text { heights are greater than widths. }\end{array}$ & $\begin{array}{l}\text { SMI-11 } \\
\text { ? }\end{array}$ \\
\hline
\end{tabular}

Figure 2: Correlation between CVMI and SMI

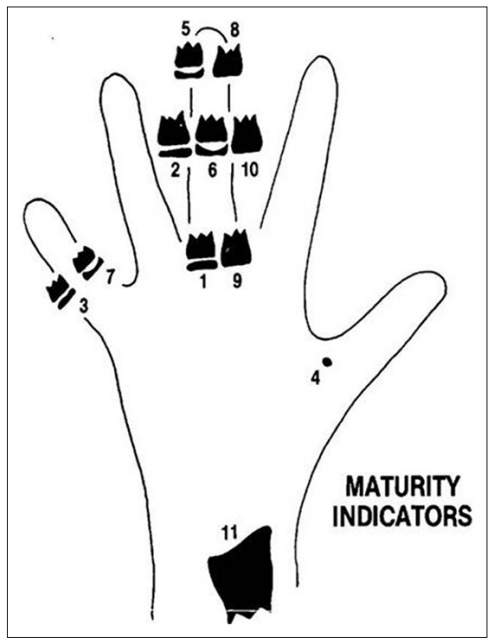

Figure 3: Eleven skeletal maturity indicators

\section{Error of measurements}

To evaluate the magnitude of error in the measurements of various stages of skeletal maturation by using hand wrist radiograph and lateral cephalogram, a double determination was carried out on 10 individual at an interval of 15 days. These tracings were analyzed separately and two sets of reading were obtained from each case. The reliability of the measurements taken was tested by T-test. Since the difference between the means of the entire variable was found to be insignificant, this means that the observations recorded in the whole study are reliable.

\section{Statistical analysis}

The data obtained were subjected to statistical analysis. Mean, standard deviation and standard error were calculated for all the groups correlation coefficients were computed for the samples collected. The student 'Newman-Keuls test' was employed to evaluate the difference between the mean values of chronological age and skeletal maturations.

1. Mean

2. Standard deviation

3. Standard error

4. Newman-Keuls test (NKT)

5. Student T-test

6. Correlation coefficient

\section{RESULTS}

These Tables 2 and 3 shows the pattern of all the three subgroups for both male and female that is $\left(a_{1}, b_{1}, c_{1}\right)$ and $\left(\mathrm{a}_{2}, \mathrm{~b}_{2}, \mathrm{c}_{2}\right)$ relatively increased mean with age when assessing SMI stages, CVMI stages. This table also indicates that age assessed by SMI and age assessed by CVMI both are higher than chronologic age. This is same for both groups male and female.

Tables 4 and 5 shows age assessed by SMI and CVMI for both male and female. According to these tables females matures earlier then male.

\section{Table 2: Mean value, standard deviation and standard error for different variables in Group 1: Male}

\begin{tabular}{|c|c|c|c|c|c|c|c|c|c|}
\hline \multirow[t]{2}{*}{ Variable } & \multicolumn{3}{|c|}{$\begin{array}{l}\text { Sub group } a_{1} \\
(10-11 \text { years) }\end{array}$} & \multicolumn{3}{|c|}{$\begin{array}{l}\text { Sub group } b_{1} \\
\text { (11-12 years) }\end{array}$} & \multicolumn{3}{|c|}{$\begin{array}{l}\text { Sub group } c_{1} \\
\text { (12-13 years) }\end{array}$} \\
\hline & Mean & SD & SE & Mean & SD & SE & Mean & SD & SE \\
\hline $\begin{array}{l}\text { Chronological } \\
\text { age }\end{array}$ & 10.47 & 0.29 & 0.07 & 11.56 & 0.20 & 0.05 & 12.15 & 0.26 & 0.07 \\
\hline SMI stage & 1.53 & 0.64 & 0.17 & 2.67 & 0.49 & 0.13 & 3.60 & 0.74 & 0.19 \\
\hline $\begin{array}{l}\text { Age assessed } \\
\text { by SMI }\end{array}$ & 11.35 & 0.40 & 0.10 & 11.97 & 0.20 & 0.05 & 12.29 & 0.30 & 0.08 \\
\hline CVMI stage & 1.13 & 0.35 & 0.09 & 1.87 & 0.35 & 0.09 & 2.20 & 0.41 & 0.11 \\
\hline $\begin{array}{l}\text { Age assessed } \\
\text { by CVMI }\end{array}$ & 11.69 & 0.25 & 0.06 & 12.21 & 0.25 & 0.06 & 12.48 & 0.37 & 0.10 \\
\hline
\end{tabular}




\begin{tabular}{|c|c|c|c|c|c|c|c|c|c|}
\hline \multirow[t]{2}{*}{ Variable } & \multicolumn{3}{|c|}{$\begin{array}{l}\text { Sub group } a_{2} \\
(9-10 \text { years })\end{array}$} & \multicolumn{3}{|c|}{$\begin{array}{l}\text { Sub group } b_{2} \\
(10-11 \text { years })\end{array}$} & \multicolumn{3}{|c|}{$\begin{array}{l}\text { Sub group } c_{2} \\
(11-12 \text { years) }\end{array}$} \\
\hline & Mean & SD & SE & Mean & SD & SE & Mean & SD & SE \\
\hline $\begin{array}{l}\text { Chronological } \\
\text { age }\end{array}$ & 9.41 & 0.21 & 0.06 & 10.46 & 0.28 & 0.07 & 11.52 & 0.29 & 0.08 \\
\hline SMI stage & 1.87 & 0.35 & 0.09 & 3.33 & 0.49 & 0.13 & 5.93 & 0.88 & 0.23 \\
\hline $\begin{array}{l}\text { Age assessed } \\
\text { by SMI }\end{array}$ & 10.51 & 0.25 & 0.06 & 11.00 & 0.15 & 0.04 & 11.97 & 0.31 & 0.08 \\
\hline CVMI stage & 1.00 & 0.00 & 0.00 & 2.07 & 0.26 & 0.07 & 3.07 & 0.46 & 0.12 \\
\hline $\begin{array}{l}\text { Age assessed } \\
\text { by CVMI }\end{array}$ & 10.40 & 0.00 & 0.00 & 11.77 & 0.28 & 0.07 & 11.86 & 0.47 & 0.12 \\
\hline \multicolumn{10}{|c|}{$\begin{array}{l}\text { SD - Standard deviation; SE - Standard error; SMI - Skeletal maturation indicator; } \\
\text { CVMI - Cervical vertebral maturation indicator }\end{array}$} \\
\hline \multicolumn{10}{|c|}{$\begin{array}{l}\text { Table 4: Age assessment by SMI (years) for both male } \\
\text { and female }\end{array}$} \\
\hline \multicolumn{4}{|c|}{ Skeletal maturation indicator } & \multicolumn{3}{|c|}{ Males age } & \multicolumn{3}{|c|}{ Female age } \\
\hline \multicolumn{4}{|c|}{ SMI 1} & \multicolumn{3}{|c|}{11.0} & \multicolumn{3}{|c|}{9.0} \\
\hline \multicolumn{4}{|l|}{ SMI 2} & \multicolumn{3}{|c|}{11.7} & \multicolumn{3}{|c|}{10.6} \\
\hline \multicolumn{4}{|l|}{$\mathrm{SMI} 3$} & \multicolumn{3}{|c|}{12.1} & \multicolumn{3}{|c|}{10.9} \\
\hline \multicolumn{4}{|l|}{$\mathrm{SMI}_{4}$} & \multicolumn{3}{|c|}{12.3} & \multicolumn{3}{|c|}{11.2} \\
\hline \multicolumn{4}{|l|}{ SMI 5} & \multicolumn{3}{|c|}{13.0} & \multicolumn{3}{|c|}{11.6} \\
\hline \multicolumn{4}{|l|}{ SMI 6} & \multicolumn{3}{|c|}{13.8} & \multicolumn{3}{|c|}{12.0} \\
\hline \multicolumn{4}{|l|}{ SMI 7} & \multicolumn{3}{|c|}{14.4} & \multicolumn{3}{|c|}{12.3} \\
\hline \multicolumn{4}{|l|}{ SMI 8} & \multicolumn{3}{|c|}{15.1} & \multicolumn{3}{|c|}{13.1} \\
\hline \multicolumn{4}{|l|}{ SMI 9} & 15 & 5.5 & & & 13.9 & \\
\hline SMI 10 & & & & 16 & 5.4 & & & 14.8 & \\
\hline SMI 11 & & & & 17 & 7.4 & & & 16.1 & \\
\hline
\end{tabular}

\begin{tabular}{lcc}
\hline $\begin{array}{l}\text { Table 5: Age assessed by CVMI (years) for both male } \\
\text { and female }\end{array}$ & \\
$\begin{array}{l}\text { Cervical vertebrae } \\
\text { maturity indicator }\end{array}$ & Males age) & Female age \\
\hline CVMI-1 & 11.6 & 10.4 \\
CVMI-2 & 12.3 & 10.7 \\
CVMI-3 & 13.2 & 11.8 \\
CVMI-4 & 14.2 & 12.8 \\
CVMI-5 & 15.7 & 14.3 \\
CVMI-6 & 17.2 & 16.5 \\
\hline
\end{tabular}

CVMI - Cervical vertebral maturation indicator

Table 6: Showing comparison of chronologic age with age by SMI, and age by CVMI, There are significant result is obtained for both groups except subgroup $\mathrm{c}_{1}$ and $\mathrm{c}_{2}$, because $c_{1}$ (12-13 years for males) and $c_{2}$ (11-12 years for females) are at growth spurt.

Table 7 shows a significant correlation between age assessed by SMI and age assessed by CVMI in all the three subgroups of male subjects. This correlation is positive which indicates the change of ages in the same direction. The strong correlation was observed in $\mathrm{c}_{1}$ subgroup.
In females the different patterns were observed than in males. Since the stage of SMI was same in all the patients of 9-10 years age group, therefore, the correlation between age by SMI and other variables was zero. A significant correlation $(r=0.884)$ between age by SMI and age CVMI was found in the age group (11-12 years subgroup).

The coefficient of correlation between age by SMI and age by CVMI increases by the advancement of ages in both male and female groups.

\section{DISCUSSION}

The search has been continuously made to find a method by which the developmental status of a child could be ascertained as the child growth pattern is highly individualized and there is great variation in the developmental status of children of identical chronological ages Burstone. ${ }^{[6]}$

In the present study the comparison was made between chronological age and age assessed by SMI, CVMI and to assess the reliability of CVMI, as SMI.

Further in this study correlation was made between SMI age, and CVMI age, assessing the reliability of chronological age as a skeletal maturity indicator as compared to SMI age, CVMI age.

In the present study, there is a significant difference between chronological age and age assessed by SMI $\left(6.89^{* *}\right)$, and age assessed by CVMI $\left(9.56^{* *}\right)$. This indicates that skeletal maturation is more advance then chronological age. Lamparski ${ }^{[4]}$ was a first person to utilize the cervical vertebrae radiographically and found them to be as reliable and valid as the hand-wrist radiography for assessing skeletal age. This view was supported by Fishman et al..$^{[5,7,8]}$ in their study they confirm skeletal age is more advance than chronological age. This study is also supported by Hunter, ${ }^{[9]}$ Schour and Masseler. ${ }^{[10]}$

When correlative study is done, strong correlation was found out between age by SMI and age by CVMI in both males and females $\left(0.849^{* *}\right.$ and $\left.0.932^{* *}\right)$. This suggests that as SMI used for assessing skeletal age CVMI can also be used for assessing skeletal age. This study is supported by Lamparski ${ }^{[4]}$ and Hassel and Farman ${ }^{[1]}$ Kucukkeles N, Acar A, Biren S, Tulin A, ${ }^{[11]}$ Hellsing, ${ }^{[12]}$ in his study presented that the height of the vertebral bodies was greater among the girls than the boys at each age.

The CVMI can be applied to determine the optimal treatment time in orthodontics to eliminate exposing an extra hand-wrist radiograph. The CVMI has an advantage for the assessment of the peak of growth. ${ }^{[13]}$ The CVMI can be determined on the lateral cephalometric 


\begin{tabular}{|c|c|c|c|}
\hline \multicolumn{4}{|c|}{$\begin{array}{l}\text { Table 6: Comparison of chronologic age with age by } \\
\text { SMI, and age by CVMI }\end{array}$} \\
\hline Sub groups & $\begin{array}{l}\text { No. of } \\
\text { subject }\end{array}$ & $\begin{array}{c}\text { Comparison } \\
\text { between } \\
\text { chronological age } \\
\text { and age by SMI }\end{array}$ & $\begin{array}{c}\text { Comparison } \\
\text { between } \\
\text { chronological age } \\
\text { and age by CVMI }\end{array}$ \\
\hline \multicolumn{4}{|c|}{ Group I: Males } \\
\hline$a_{1}$ & 15 & $6.89 * *$ & $9.56 * *$ \\
\hline$b_{1}$ & 15 & $4.67^{* *}$ & $7.53^{* *}$ \\
\hline$c_{1}$ & 15 & NS & NS \\
\hline \multicolumn{4}{|c|}{ Group II: Females } \\
\hline$a_{2}$ & 15 & $11.10 * *$ & $10.03^{* *}$ \\
\hline$b_{2}$ & 15 & $6.02 * *$ & $3.49 *$ \\
\hline$c_{2}$ & 15 & NS & NS \\
\hline
\end{tabular}

\begin{tabular}{|c|c|}
\hline \multicolumn{2}{|c|}{$\begin{array}{l}\text { Table 7: Correlation coefficient }(r) \text { between different } \\
\text { variables in each subgroup }\end{array}$} \\
\hline & $\begin{array}{l}\text { Between age assessed by SMI and } \\
\text { age assessed by CVMI ' } r \text { ' value }\end{array}$ \\
\hline \multicolumn{2}{|c|}{ Group I: Males } \\
\hline$a_{1}$ & $0.550^{*}$ \\
\hline$b_{1}$ & $0.0554^{*}$ \\
\hline$c_{1}$ & $0.816 * *$ \\
\hline \multicolumn{2}{|c|}{ Group II: Females } \\
\hline$a_{2}$ & 0.000 \\
\hline$b_{2}$ & 0.379 \\
\hline$c_{2}$ & $0.889 * *$ \\
\hline
\end{tabular}

radiograph, which is a radiograph regularly being used in orthodontics for other treatment planning purposes..$^{[14]}$ Cervical vertebrae development is reliable and valid in the assessment of skeletal and somatic maturity. They found that the reliability and validity of the CVMI was acceptably high and could replace the hand wrist radiograph approach in the assessment of skeletal and somatic maturity. ${ }^{[15]}$

To conclude, it could be stated that assessment of maturation is of utmost importance in certain orthodontic protocols like for myofunctional therapy, before starting with rapid maxillary expansion and for timing of ortho-surgical procedures (surgery for mandibular setback should carried out only after mandibular growth has completed). As chronological age cannot show accurate status of individual's skeletal age, skeletal age could be assessed by time tested hand wrist radiographs or by CVMI to further validate the results of this study, it should be carried out on larger sample size and varied age groups.

\section{CONCLUSION}

1. Skeletal maturation is more advance in comparison of chronologic age as assessed with the help of SMI and CVMI in both male and female.

2. Strong correlation was found between SMI age and CVMI age. This suggests that CVMI can also be used as a SMI.

3. The CVMI method also presents the advantage of using the lateral cephalogram, which is a basic record for orthodontic diagnosis.

4. Low correlations were found between chronological age and SMI, and between chronological age and CVMI, not rely on chronological age.

\section{REFERENCES}

1. Hassel B, Farman AG. Skeletal maturation evaluation using cervical vertebrae. Am J Orthod Dentofac Orthop 1995;107:58-66.

2. Bjork A, Helm S. Prediction of the age of maximum pubertal growth in body height. Angle Orthod 1967;37:134-43.

3. Gupta S, Sharma A, Grewal H: Pubertal growth spurt in orthodontics. J Ind Orthod Soc 1998;31:17-20.

4. Lamparski D. Skeletal age assessment utilizing cervical vertebrae [Thesis]. Pittsburgh: University of Pittsburgh, 1972. (cited from Am J Orthod 1995;107:55-8).

5. Fishman LS. Radiographic evaluation of skeletal maturation. A clinically oriented method based on Hand-wrist films. Angle Orthod $1981 ; 52 ; 88-112$.

6. Burstone. Process of maturation and prediction. Am J Orthod 1963;49:907-19.

7. Fishman LS. Chronological versus skeletal age, an evaluation of craniofacial growth. Angle Orthod 1979;49:181-9.

8. Fishman. Maturation pattern and prediction during adolescence. Angle Orthod 1987;57:178-93.

9. Hunter. The correlation of facial growth with body height and skeletal maturation at adolescence. Angle Orthod 1966;36:44-54.

10. Schour, Massler. The development of the human dentition. JADA 1941;1153-60.

11. Kucukkeles N, Acar A, Biren S, Tulin A. Comparisons between cervical vertebrae and hand-wrist matura-tion for the assessment of skeletal maturity. J Clin Pediatr Dent 1999;24:47-52.

12. Hellsing E. Cervical vertebral dimensions in 8-, 11- and 15-year old children. Acta Odontol Scand 1991;49:207-13.

13. Hagg U, Taranger J. Maturation indicators and the pubertal growth spurt. Am J Orthod 1982;82:299-309.

14. Szyska M, Pancherz H. The cervical vertebrae (C3) in skeletal and somatic maturation evaluation. Eur J Orthod 1999;21:624.

15. García-Fernandez P, Torre H, Flores L, Rea J. Skeletal age assessment: Comparative study between cervical vertebrae and hand-wrist maturation. In: Farman AG, Ruprecht A, Gibbs SJ, Scarfe WC, editors. Advances in Maxillofacial Imaging. IADMFR/ CMI'97. Amsterdam: Elsevier; 1997. p. 215-22.

How to cite this article: Kiran S, Sharma VP, Tandon P. Correlative and comparative study of Fishman's skeletal maturity indicators with CVMI and chronological age in Lucknow population. Eur J Gen Dent 2012;1:161-5.

Source of Support: Nil, Conflict of Interest: None declared. 